\title{
INSTRUMENTOS PARA LIDAR COM A OCUPAÇÃO DESORDENADA EM ÁREAS DE RISCO: O caso Cidade do Povo
}

\section{INSTRUMENTS TO DEAL WITH DISORDERED OCCUPATION IN AREAS OF RISK: The case of Cidade do Povo}

\author{
A. Emerson D. Simplício dos Santos \\ Universidade de Lisboa, Portugal \\ emersonsimplicio@hotmail.com
}

\begin{abstract}
RESUMO
Este trabalho apresenta uma discussão sobre a realocação de famílias, moradoras de áreas de risco, enquanto instrumento urbanístico. A literatura abordada analisa essas duas questões, mostrando que as famílias de menor poder aquisitivo tendem a procurar habitações em regiões em que esteja facilitado o acesso aos serviços públicos, ainda que as áreas ocupadas sejam insalubres ou ocasionem riscos físicos aos moradores. Após o direcionamento teórico, são apresentados e avaliados os motivos para a ocorrência dessas ocupações, em especial a não aplicação do princípio social da propriedade e o não cumprimento do direto à habitação previsto na lei brasileira. Como exemplo de utilização do instrumento de realocação de famílias é apresentada a Cidade do Povo, empreendimento habitacional em Rio Branco, capital do estado do Acre, que buscou resolver a questão de milhares de famílias que viviam em áreas de risco, entretanto, questões diversas contribuem para a não inclusão social dessas pessoas.
\end{abstract}

Palavras-chave: Urbanismo, ocupação desordenada, segregação socioespacial, moradia.

Linha de Investigação: Dinâmicas urbanas.

Tópico: Assentamentos precários..

\begin{abstract}
This paper presents a discussion on the relocation of families, living in risk areas, as an urban instrument. The consulted literature analyzes these two issues, showing that families with lower purchasing power tend to look for housing in regions where access to public services is facilitated, even though the occupied areas are unhealthy or cause physical risks to the residents. After the theoretical guidance, the reasons for the occurrence of these occupations are presented and evaluated, especially the non-application of the social principle of property and the non-compliance with the right to housing presents in the Brazilian law. As an example of using the family relocation instrument, Cidade do Povo is presented, a housing development in Rio Branco, capital of the state of Acre, which sought to resolve the issue of thousands of families living in risk areas, however, several issues contribute for the social exclusion of these people.
\end{abstract}




\section{SÃOPAULO15 17 LISBOA $25 \sim 26$ JUN 2020}

Research line: Urban Dynamics.

Topic: Precarious settlements.

\section{Introdução: ocupação desordenada em áreas de risco}

O aumento no número de habitantes das grandes cidades provoca fenômenos diversos. Em países em desenvolvimento, um dos efeitos desse crescimento é a ocupação desordenada do solo urbano. Acontecimento agravado pela incapacidade de se criar e gerir políticas públicas habitacionais eficazes, por parte os governantes. Essas pessoas - que ficam à margem do acesso à terra urbana - ocupam, sobretudo, áreas que são declaradas como não-edificantes.

Como fenômeno global, as taxas de urbanização do planeta crescem de forma exponencial. Trata-se de uma urbanização intensa e desordenada, com a maior parte das cidades sem condições de absorver tal contingente (Luiz, 2009).

Os espaços ocupados, em geral, estão localizados em terrenos com risco de escorregamento ou integram áreas de preservação permanente. É cada vez mais comum no noticiário a presença de desastres em áreas que sofreram com enchentes ou deslizamentos de terra; consequências de uma ocupação desordenada no espaço urbano. Por falta de recursos, a população menos favorecida acaba ocupando espaços que trazem não somente prejuízos materiais e riscos físicos para seus ocupantes como também acarretam danos ao meioambiente.

Não é possível apontar um único fator para a ocorrência da ocupação desordenada, ela ocorre por uma conjunção de vários fatores, tais como a falta de uma política séria sobre o ordenamento urbano. E ainda devido à omissão nas ações de fiscalização, que, em muitos lugares, só ocorrem após o aparecimento de algum desastre natural.

De acordo com um estudo do Banco Mundial, realizado em 2002, cerca de cinquenta por cento da população do planeta tentava sobreviver com menos de dois dólares por dia. Outro dado alarmante demonstra que milhões de pessoas, nos países em desenvolvimento, não possuem moradia, nem em ocupações formalizadas pelo poder público, nem tampouco em terrenos regularizados (Miller, 2008).

É importante deixar claro que a ocupação de áreas de risco e o mau uso do solo urbano, embora aconteça com maior intensidade nas camadas sociais de menor poder aquisitivo, não é um fenômeno exclusivo destas. O modo irracional do uso dos recursos urbanos, bem como a falta de cumprimento das legislações ambientais existentes, ocorre, também, em outros estratos sociais (Miller, 2008).

Devemos considerar ainda, para melhor enfrentamento do problema, que a ocupação urbana de áreas de risco, para a edificação de moradias, como encostas de morros e várzeas de rios, é um processo que não se desenvolve apenas nas grandes cidades, aonde a desigualdade social é mais profunda e, o acesso à terra, um produto caro; ela ocorre também aonde quer que não exista um planejamento urbano com políticas públicas inclusivas e defesa da função social da propriedade (Brasil, 2011). 


\section{XII $\mathbf{S A ̃ O P A U L O} 15 \sim 17 \cdot$ LISBOA $25 \sim 26$ JUN 2020}

\section{$\mathrm{O}$ direito à moradia}

No Brasil a busca por justiça social está presente na Constituição Federal, datada de 1988. O documento, idealizado após período ditatorial militar, busca enfatizar a necessidade de procura por uma sociedade igualitária, onde todos poderão exercer sua cidadania de forma plena:

[...] consagrou uma ampla gama de direitos fundamentais. Afora os direitos individuais clássicos, garantidos desde o advento do constitucionalismo liberalburguês, ela contemplou também direitos sociais, como a saúde e o salário mínimo; políticos, como o direito de votar e ser votado; e coletivos, como o direito ao meio ambiente e à proteção da cultura. Além dos direitos universais, titularizados por todos, ela garantiu ainda direitos fundamentais específicos para indivíduos e grupos mais vulneráveis, como as pessoas com deficiência, crianças e adolescentes, idosos, povos indígenas e quilombolas. (Souza Neto; Sarmento Neto, 2012: 250)

Assim sendo, a Constituição Federal Brasileira (1988) incluiu como um dos seus principais apontamentos a procura pela garantia de um bem-estar social mínimo ao incorporar a dimensão social. É necessário que o Estado forneça as bases para que seja garantida a "segurança contra os infortúnios e incertezas da vida; para a segurança como garantia de direitos sociais básicos para os excluídos; e até para a segurança em face das novas tecnologias e riscos ecológicos (...)" (Souza Neto; Sarmento Neto, 2012).

O texto original (1988) já tratava do tema, porém de forma indireta o que gerava questionamentos sobre sua aplicabilidade. O direito à moradia, no território brasileiro, foi expressamente incluído na Constituição Federal, através da emenda constitucional de número 26, no ano 2000.

"Art. $7^{\circ}$ São direitos dos trabalhadores urbanos e rurais, além de outros que visem à melhoria de sua condição social: [...] V - salário mínimo, fixado em lei, nacionalmente unificado, capaz de atender a suas necessidades vitais básicas e às de sua família com moradia, alimentação, educação, saúde, lazer, vestuário, higiene, transporte e previdência social, com reajustes periódicos que lhe preservem o poder aquisitivo, sendo vedada sua vinculação para qualquer fim; [...]" (Brasil, 2000).

É papel do Estado garantir os direitos sociais fundamentais e que estes devem compreender duas dimensões, uma defensiva, em que o papel dos governantes é evitar que suas próprias condutas possuam efeitos negativos às instituições instaladas. A segunda dimensão seria o papel de prestador de serviço sobre a qual o Estado deve agir para suprir os direitos à segurança, educação, saúde e habitação. Santos (1997) esclarece que, quando do direcionamento na prestação dos seus serviços, o Estado deve sempre abraçar aqueles que necessitam de ajuda imediata, por não possuírem meios para tal.

No Brasil, como um país em desenvolvimento que apresenta elevados índices de desigualdade social, com números acachapantes de violência urbana e elevado número de pessoas pobres e miseráveis, existem milhões de pessoas sem acesso à moradia legalizada e sem direito a uma infraestrutura mínima. Dados apresentados em 2019 pela Fundação Getúlio Vargas (FGV), em parceria com a Associação Brasileira de Incorporadoras Imobiliárias, demonstravam que o déficit habitacional no Brasil, em 2017, chegou a 7,78 milhões de unidades habitacionais. Essa carência por moradias é refletida em mais ocupações, sejam de edifícios abandonados, terrenos subutilizados ou de áreas em situação de risco (ABRAINC, 2018). 


\section{SÃOPAULO15 17 LISBOA $25 \sim 26$ JUN 2020}

\section{O Estatuto da Cidade}

Criada como lei para garantir a função social da propriedade urbana (prevista na Constituição de 1988), o Estatuto da Cidade (2001) exige a elaboração de Plano Diretor urbanístico em todas as cidades com mais de 20.000 habitantes, integrantes de conglomerados urbanos e regiões metropolitanas, de grande potencial turístico ou onde se desenvolva atividade econômica de grande impacto ambiental.

O Estatuto da Cidade (2001) trouxe consigo uma série de instrumentos para, além de garantir o direcionamento do uso do solo urbano para o bem coletivo, tentar controlar a especulação imobiliária. Fenômeno que vem sendo apontado como o principal fator que dificulta o acesso aos terrenos em áreas com melhor infraestrutura e acesso aos serviços.

Uma grande parte dos municípios brasileiros não implementa os instrumentos previstos no Estatuto da Cidade. Pesquisa realizada em 2015 pela Confederação Nacional dos Municípios (CNM) revelou que, embora 99\% dos municípios brasileiros com mais de cem mil habitantes já possuíam Planos Diretores, apenas 32\% (ou 91 municípios) haviam regulamentado em sua legislação o instrumento denominado Parcelamento, Edificação ou Utilização Compulsórios (PEUC), bem como a cobrança de um IPTU (Imposto Predial e Territorial Urbano) progressivo sobre imóveis subutilizados.

Em uma segunda etapa, do mesmo estudo, foi verificada a efetividade da lei. A conclusão foi de que apenas 25 municípios possuíam legislação de forma a torná-la aplicável (CNM, 2015).

A preocupação com o tema é constante, projeto de lei do Senado Federal em tramitação desde o ano de 2011, busca tornar obrigatório também a elaboração de Planos Diretores em qualquer município que possuam áreas consideradas de risco em seu território, ampliando a obrigatoriedade atual, que é baseada apenas no número de habitantes das cidades (Brasil, 2011).

Não obstante é necessário considerar ainda a ineficiência do poder público em garantir que se cumpram as legislações ambientais em vigor, que possuem regramentos em outras leis (para além do Estatuto da Cidade:

A educação ambiental no Brasil, após anos de lutas dos ambientalistas, começou a ter um certo reconhecimento no cenário nacional na década de 90 , cujo ápice foi a promulgação da Lei № 9.795, em 28 de abril de 1999, instituindo a Política Nacional de Educação Ambiental. Isso não significa, no entanto, a sua consolidação ou assunção de sua centralidade.; apenas trata-se do seu reconhecimento político. Menos ainda há consenso sobre sua compreensão, natureza ou princípio (Saito, 2002: 49).

Muito embora existam leis que protegem áreas ambientais, estas estão entre as mais visadas pela população que ocupam áreas de risco. A legislação que define a proteção de uma faixa de domínio ao longo dos cursos de água, por exemplo, é do ano de 1979, porém essas áreas continuam sendo ocupadas nas cidades brasileiras (Brasil, 1979).

Apesar da busca recorrente em se utilizar a legislação como um instrumento para tratar o desafio de controlar a ocupação de áreas de risco, os dados comprovam (pelo menos no caso brasileiro) que, seja demonstrando que as cidades não aplicam a legislação de forma eficaz, seja devido a incapacidade do Estado em controlar novas ocupações, o poder público não consegue transformar os instrumentos em políticas efetivas para solucionar ou mitigar o problema. 


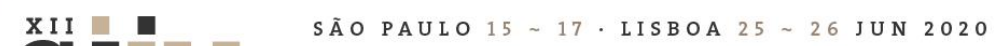

\section{Minha Casa Minha Vida}

Um outro instrumento utilizado pelos governos, para sanar o déficit habitacional e evitar a ocupação das áreas de risco, é a realocação dos moradores dessas áreas para conjuntos construídos através de programas instituídos por várias esferas governamentais.

Um dos mais importantes programas perdurou por mais 20 anos no Brasil (1964-1986), foi o programa de habitação chamado de Sistema Financeiro de Habitação (SFH) que tinha sua implantação acompanhada do Banco Nacional de Habitação (BNH) (Maricato, 1995). A base dessa nova política habitacional era o acesso a casa própria, visando a eliminação das ocupações irregulares (chamadas, em geral, de favelas) (Villaça, 1986).

Extinto em 1986 o BNH, já com um enorme rombo orçamentário (NEPP/UNICAMP, 1991), deu vez a diversos outros programas habitacionais. Porém o mais famoso e mais bem-sucedido destes foi o Programa Minha Casa Minha Vida (PMCMV) do Governo Federal Brasileiro que teve um impacto em todo o território nacional. Iniciado no ano de 2009, estima-se que até 2018 mais de 5 milhões de unidades habitacionais foram adquiridas. Boa parte das moradias desses programas são subsidiadas, podendo até ter custo zero para pessoas de baixa renda ou que se encontram ocupando áreas de risco (Holanda, 2011).

\section{Cidade do Povo (Rio Branco-AC)}

Como muitas cidades amazônicas, Rio Branco, capital do estado do Acre, encontra-se em meio a diversos cursos de água, sejam rios, igarapés ou pequenos córregos. Fundada no ano de 1882 a cidade surgiu a partir de um seringal, sendo assentada ao longo de um rio (Cordeiro; Schimink, 2009).

Os primeiros "bairros" de Rio Branco, inclusive, se estabeleceram perto de cursos d'águas: Canudos se estabeleceu em volta do rio Acre na parte que hoje é conhecida como a Gameleira; o bairro do Centro também se situou ao longo do rio Acre; por fim temos a ocupação da Rua África uma extensão de rua em direção ao igarapé da Judia (Neves, 2006).

Desta forma o traçado urbano do Município não atendeu parâmetros de urbanização, tendo muitos dos seus bairros sendo formados por invasões. Analisando-se os dados do IBGE verificamos que entre as décadas de 1960 e 1970 a população de Rio Branco praticamente dobrou. Na década de 1960 eram 47.437 habitantes, (30.333 pessoas na zona rural e 17.104 na urbana), na década de 1970 a população rio-branquense era formada por 83.977 habitantes - sendo 48.399 habitantes na zona rural e 35.578 na zona urbana - (Lima, 2006).

Nesse período a cidade de Rio Branco não possuía lei de parcelamento e uso do solo com parâmetros definidos. As poucas leis existentes que regulamentavam o parcelamento e o uso da propriedade do solo urbano eram ignoradas por loteadores, grileiros e usuários, inclusive às legislações federais.

A mancha urbana da cidade ampliou-se nas décadas de 1970 e 1980, no contexto da frente agropecuária. A expulsão das terras e o movimento migratório foram os fenômenos mais intensos nos primeiros anos da chegada dos agropecuaristas ao Vale do Acre-Purus. Com as terras sendo progressivamente ocupadas por novos donos, é desencadeado o processo migratório de seringueiros, índios, posseiros e ribeirinhos para Rio Branco. Os problemas imediatos desse fluxo migratório para Rio Branco foram o surgimento de loteamentos clandestinos em locais onde faltava todo tipo de infraestrutura. (Morais; Venturato, 2000: 95) 


\section{XII $\quad$ SÃOPAULO $15 \sim 17 \cdot$ LISBOA $25 \sim 26$ JUN 2020

Em 1986 foi criado o Plano Diretor de Desenvolvimento de Rio Branco, que era a lei de parcelamento e uso do solo (Lei Municipal № 612/86), instituído no ano de 1986, este plano definia, ao longo de vários cursos de água presentes na cidade, as chamadas Zonas Verdes (ZV). Essas zonas possuíam parâmetros urbanísticos que evitavam o adensamento dessas áreas, procurando preservar as margens dos chamados fundos de vale.

Do mesmo modo é importante lembrar que além da lei municipal estava em vigor na época (e ainda hoje) a Lei Federal de № 6.766 do ano de 1979 - que dispõe sobre o parcelamento do solo urbano. Esta lei define, em seu artigo 40, que ao longo de todas as águas correntes e dormentes será obrigatória uma reserva de faixa non aedificandi de 15 (quinze) metros de cada lado (esse artigo da referida lei foi alterada pela Lei № 10.932/2004).

Apesar das legislações existentes, as ocupações continuaram a acontecer, e as cheias sazonais do Rio Acre fazem com que várias famílias precisem de auxílio, mesmo que momentâneo, do Município e do Governo do Estado, que arcam com as despesas das emergências criadas.

Atualmente, Rio Branco é uma das capitais brasileiras com maior número de pessoas em situação de pobreza. Dados do ano de 2011 apresentavam um quadro preocupante frente à situação socioeconômica da população acreana, segundo dados do IBGE (2010), uma vez que $18 \%$ da população do Acre encontrava-se na faixa da extrema pobreza e, com essa conjuntura, muitos outros problemas vinham em cadeia, como é o caso da segurança pública.

De acordo com o último censo do IBGE realizado em 2010 o déficit de moradias do Acre era de 28 mil moradias. Com a entrega de mais de sete mil unidades habitacionais nos últimos três anos, esse número baixou para aproximadamente 20 mil. $^{1}$

Foi na esteira desse cenário, e considerando o déficit habitacional existente no estado do Acre e no município de Rio Branco, que foram elaborados os primeiros estudos sobre a situação de moradia dos habitantes da capital do Estado do Acre, tomou forma - numa ação conjunta do Governo Estadual e a Prefeitura Municipal de Rio Branco - o Plano Municipal de Habitação de Interesse Social de Rio Branco (PMHIS).

O Plano Municipal de Habitação de Interesse Social de Rio Branco (PMHIS) de 2011 detalha que a cidade de Rio Branco teve uma significativa alteração em sua estrutura urbana na última década, ao contrário dos anos anteriores que só se caracterizam pelo aumento da malha urbana e da massa periférica. Mas o aumento não foi só quanto a sua estrutura como cidade, sendo também um aumento de $32,79 \%$ na sua população nos últimos dez anos, apresentando um acréscimo de "29.842 moradores, apenas entre 2009 e 2010 , uma taxa significativa de $2,82 \%$, enquanto a taxa de crescimento no Acre é de $2,09 \%$ ao ano, e constitui a terceira maior taxa dentre os estados brasileiros". (IBGE, 2010)

Com os estudos, que se iniciaram em 2009 (mesmo ano da implantação do Programa Minha Casa Minha Vida), iniciou-se a efetivação de ações que pretendiam a regularização fundiária da cidade em combate aos parcelamentos irregulares, assentamentos informais dentre outros problemas que precisavam ser resolvidos.

Entre as questões que necessitavam uma resposta imediata, através do PMHIS, estava a realocação das famílias vítimas das alagações sazonais do Rio Acre, considerado como um dos maiores problemas de Rio

\footnotetext{
${ }^{1}$ Disponível em: <https://agencia.ac.gov.br/com-a-execucao-da-cidade-do-povo-acre-sera-um-dos-estados-com-menor-indice-de-deficithabitacional/>. Acesso em jul. 2020.
} 


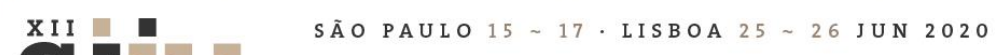

Branco, buscou-se alternativas para realojar essas pessoas longe das áreas de risco, estudos foram realizados de forma a encontrar locais passíveis de aplicação dos recursos oficiais provenientes do Programa Minha Casa Minha Vida.

De acordo com Oliveira (2011), pelo menos dez porcento da população urbana de Rio Branco morava em áreas que, conforme o Plano Diretor de Rio Branco de 2006, estavam sujeitas a enchentes ou deslizamentos. Estas famílias são compostas, em sua maioria, por pessoas de baixa renda que ocupam residências de madeira com poucos cômodos (Morais; Venturato, 2013).

Nos anos de 2012 e 2015 a cheia do Rio Acre atingiu quase noventa mil pessoas - o equivalente a cerca de $20 \%$ da população da cidade. ${ }^{2}$ Já os dados das 181 famílias cadastradas após a enchente de 2010, que necessitaram de auxílio do poder público após ficarem desabrigadas, comprovam a vulnerabilidade socioeconômica e habitacional a que estas famílias enfrentam (Oliveira, 2011).

O empreendimento urbanístico, assim como as habitações a serem construídas, necessitavam seguir as exigências mínimas adotadas pelas regras do programa - que vão além do existente em leis anteriores ao cobrarem a implantação de uma infraestrutura mínima, bem como regramentos de padrões construtivos das unidades.

Uma das soluções encontradas pela equipe de trabalho do PMHIS para que se colocasse em prática o direito constitucional à moradia digna, dotada de infraestrutura básica e com acesso à saúde, segurança e educação foi a criação da "Cidade do Povo". A Cidade do Povo foi o nome dado à política pública de integração social para pessoas de baixa renda que viviam em situações de risco e de miséria social, ocupando sobretudo as margens do Rio Acre.

A Cidade do Povo é um empreendimento imobiliário realizado em parceria entre o Estado do Acre e a iniciativa privada, com recursos do Programa Minha Casa, Minha Vida, visando suprir o déficit habitacional(quantitativo e qualitativo) do Município de Rio Branco e, especialmente, promover a dignidade das milhares de pessoas que hoje vivem nas áreas de risco de inundação do Rio Acre, com a construção de 10.600 casas beneficiando aproximadamente 60.000 pessoas. O empreendimento será instalado numa área de cerca de 700 hectares, que se encontra totalmente desmatada (pelo proprietário anterior), sem respeito às áreas de preservação permanente e à reserva legal, com o solo compactado pelo pisoteio do gado, de modo que não existe retenção de água, pois a chuva simplesmente escorre como enxurrada, causando a erosão do solo e o assoreamento dos igarapés. (ACRE Tribunal de Justiça, Ação Civil Pública, 0705226-03.2012.8.01.0001: 384)

De acordo com o PMHIS (2011) o processo de análise para escolha da área de implantação não foi fácil de alcançar, por não existir locais vazios e com preços realistas, evitando, assim, as áreas de alagações, lixões, área de risco. Apesar da referida explicação por parte do poder público, a respeito da área escolhida, existiam diversas áreas dentro do antigo perímetro urbano municipal que, caso a função social da propriedade urbana fosse aplicada, poderiam servir para implantação de conjuntos habitacionais.

2 Disponível em: <https://www.ac24horas.com/2015/03/04/cheia-do-rio-acre-ja-atinge-quase-90-mil-pessoas-na-capital/> Acesso em jul. 2020. 


\section{XII $\mathbf{S A O O P A U L O} 15 \sim 17 \cdot$ LISBOA $25 \sim 26$ JUN 2020}

Mesmo havendo vazios urbanos em Rio Branco, a área escolhida é distante do centro, prática esta comum nas cidades brasileiras. A expansão descontínua da mancha urbana aumenta as distâncias, encarece os investimentos para a implantação de serviços públicos, eleva os custos de operação e de manutenção e reduz o aproveitamento per capita dos equipamentos existentes (Bolaffi, 1982: 58). O que nos cabe perguntar é de quem são estas terras? E por que elas foram escolhidas? O empreendimento está localizado dentro da microbacia do igarapé Judia e microbacia do igarapé Belo Jardim. São cerca de 13 bairros ou comunidades onde predomina população de baixa renda ou áreas da periferia urbana. A população da área de entorno é de 18.568 habitantes, ou $5,3 \%$ da população da capital (EIARIMA, 2012). (Morais; Venturato, 2000: 107).

Situada em área que ficava fora do perímetro urbano da cidade de Rio Branco - loca onde era proibido o parcelamento do solo para fins urbanos - foi necessário criar a Lei Municipal № 1.911/2012 que alterou a Lei Municipal № 1.661/2006 (referente ao Plano Diretor Municipal), essa lei ampliou o perímetro urbano criando a área destinada para a 'Cidade do Povo', que foi classificada como uma APH - Áreas de Promoção de Habitação.

O projeto da Cidade do Povo foi construído e entregue em três etapas, a primeira etapa atendeu às pessoas atingidas pelas cheias do Rio Acre, vítimas de alagamentos em outras partes do Município e para pessoas de renda extremamente baixa, que seriam compostas de 3.348 unidades habitacionais. No total devem ser entregues 10.518 residências aos beneficiários de baixa renda, servidores estaduais e unidades comerciais.

Apesar de impactar em um acréscimo de unidades habitacionais para contemplar mais de dez mil famílias o poder público insistiu que o projeto não impactaria no acréscimo de famílias na capital acreana:

(....) a Cidade do Povo não implica no acréscimo de 60.000 pessoas à população de Rio Branco, mas na realocação de aproximadamente 60.000 pessoas que hoje vivem em situação desumana e degradante, correndo risco de vida nas enchentes do Rio Acre, num empreendimento planejado nos mínimos detalhes, livre de inundações e próximo dos empreendimentos econômicos do futuro. (ACRE -Tribunal de Justiça, Ação Civil Pública, 0705226-03.2012.8.01.0001: 387)

Já as unidades entregues durante as etapas dois e três seriam destinadas - preferencialmente - aos funcionários públicos do Estado do Acre. Quanto às unidades comerciais dessa etapa, elas passaram por processo de edital onde os interessados em investir no bairro se inscreveram para obter sua alienação. (Relatório Social Cidade do Povo, 2017)

Contando com verbas federais, o conjunto habitacional cidade do povo é um empreendimento do Governo do Estado do Acre. A área destinada à criação do bairro está localizada no segundo distrito, próximo à área de galpões industriais e logístico, com acesso pela Rodovia BR-364, Km 05, distante 12 km do centro de Rio Branco.

O local aonde foi implantado o Bairro Cidade do Povo sofreu ainda diversas críticas dos próprios moradores com relação à distância (cerca de quinze quilômetros) que o empreendimento se encontra com relação ao centro da cidade de Rio Branco - a maior parte dos moradores que receberam unidades no bairro, devido estarem em locais com risco de enchente, moravam próximos ao centro comercial e aos seus locais de trabalho. 


\section{SÃOPAULO15 17 LISBOA $25 \sim 26$ JUN 2020}

O principal e maior loteamento implantado, foi o bairro Cidade do Povo, como já descrito. Este foi inserido sob o Plano Diretor de 2016, como um novo bairro, localizase ao final do perímetro da cidade, seguindo a BR-364. O principal objetivo foi transferir as populações que habitavam as áreas de alagações prioritárias. Mais de 3.000 famílias foram deslocadas para este espaço.

O bairro Cidade do Povo segue a conformidade da lei, quanto as especificidades das habitações e os serviços necessários. Porém, assim como os demais loteamentos, 0 bairro não segue os quesitos sociais, boa parte da população tem sido inundada não pela água, mas pela distância, violência, desemprego e falta de inúmeros outros serviços. (Bonfanti, 2019: 130).

Ainda quando o conjunto habitacional contava com pouco mais 2,2 mil moradias entregues, em maio de 2015, os moradores já reclamavam da falta de segurança, postos de saúde no bairro e, ainda, sobre a baixa demanda de transporte para o local. ${ }^{3}$

Considerando que boa parte das unidades foram entregues para uso de famílias de baixa renda, a dificuldade de acesso aos outros bairros por parte dos moradores é uma realidade, alguns inclusive acabaram retornando aos seus antigos lares pela dificuldade de arcar com os custos do transporte público que continua sendo um desafio a ser resolvido pelo poder público. ${ }^{4}$

O custo de manutenção da infraestrutura do local também pesa para o governo estadual, ao periferizar o empreendimento o poder público acaba por tornar mais caro a manutenção da rede de água e esgoto, que precisa percorrer distâncias maiores do que necessitaria caso fosse implantado em um dos diversos vazios urbanos presentes no antigo perímetro urbano municipal, os problemas com a rede de esgoto ${ }^{5}$ e de abastecimento de água potável continuam constantes. ${ }^{6}$

Outro grande problema enfrentado pela população local é a violência. Dados revelam que os homicídios têm crescido de forma exponencial no bairro de 2015 para 2016 os números de homicídios cresceram de dois para dez mortes e até o primeiro semestre de 2017 já havia ocorrido outras cinco mortes (SIPCA, 2017).

Para Pimentel (2017), apesar de os idealizadores da Cidade do Povo terem afirmado que o fato de as pessoas serem retiradas de um contexto de exclusão social e terem seus direitos mais básicos garantidos acarretaria índices menores de violência urbana, o plano falhou, principalmente por ter sido implantado em partes, o que

\footnotetext{
${ }^{3}$ Disponível em: < http://g1.globo.com/ac/acre/noticia/2015/05/um-ano-depois-seguranca-e-saude-ainda-sao-desafios-nacidade-do-povo.html> Acesso em abr. 2019.
}

4 Disponível em: https://g1.globo.com/ac/acre/noticia/moradores-da-cidade-do-povo-reclamam-da-falta-de-onibus-etempo-de-espera-em-paradas.ghtml> Acesso em abr. 2019.

${ }^{5}$ Disponível em: < http://www.ecoacre.net/destaques-noticias/moradores-do-bairro-cidade-do-povo-reclama-de-esgotos/> Acesso em abr. 2019.

${ }^{6}$ Disponível em: < https://g1.globo.com/ac/acre/noticia/2019/03/26/sem-agua-ha-5-dias-moradores-da-cidade-do-povofecham-rodovia-em-rio-branco.ghtml> Acesso em abr. 2019. 


\section{SÃOPAULO15 17 LISBOA $25 \sim 26$ JUN 2020 \\ Seminário Internacional de Investigação em Urbanismo \\ Seminario Internacional de Investigación en Urbanismo}

dificultou a presença em massa do poder público no local, proporcionando desarticulações sociais. Atualmente a Cidade do Povo tem parte da sua população ameaçada e controlada por facções criminosas. ${ }^{7}$

\section{Conclusão}

Como vimos neste breve ensaio o desafio de lidar com as ocupações desordenadas em países em desenvolvimento, como o Brasil, enfrenta pormenores que necessitam de políticas públicas integradas nas mais diversas áreas.

As tentativas de se tratar o problema por meio de leis e normas - no Brasil - não vem dado certo, principalmente pela ineficiência do poder público em garantir a função social da propriedade, que é colocada em evidência tanto na Constituição Federal Brasileira (1988) como na lei que instituiu o Estatuto da Cidade (2001).

Ao se pregar a inclusão social através de mudança de população de uma realidade em que o acesso aos serviços são mais fáceis e rápidos para lugares com melhor infraestrutura e sem riscos físicos às edificações ocupadas por ela, o poder público garante a inclusão por um lado, mas acaba por excluir a população de outros modos - como acontece com as famílias realocadas na Cidade do Povo.

Assim, o desafio não deve ser apenas projetual (de desenho) e, também, não pode ser encarado como uma simples remoção das pessoas para locais planejados, retirando-as do seu contexto de ocupação irregular.

É preciso garantir que as pessoas possam gozar da sua cidadania de forma plena, ao planejador cabe pensar em todos os processos sociais existentes, e não apenas nos aspectos técnicos de um projeto de habitação (por exemplo). Só assim será possível garantir que aja, de fato, uma inclusão social e redução dos problemas advindos da exclusão socioespacial.

\section{Bibliografia}

ABRAINC (2018). Análise das necessidades habitacionais e suas tendências para os próximos dez anos. Produto 2 - Relatório Técnico Final - 2ª Versão. Associação Brasileira de Incorporadoras Imobiliárias, 2018.

ACRE (2017). Sistema Integrado de Informações da Polícia Civil do Estado do Acre. Rio Branco, 2017.

ACRE (2012). Tribunal de Justiça do Acre. Ação Civil Pública intentada pelo Ministério Público do Acre para evitar a construção da Cidade do Povo. Tribunal de Justiça ACRE. Processo n. 0705226-03.2012.8.01.0001. Poder Judiciário do Acre.

BONFANTI, D. C. (2019). O planejamento urbano e as ocupações em áreas de preservação permanente - app - no perímetro da cidade de Rio Branco, Acre. Dissertação (mestrado) - Universidade Federal de Rondônia.

BRASIL (1988). Constituição (1988). Constituição da República Federativa do Brasil. Brasília, DF: Senado Federal.

\footnotetext{
7 Disponível em: < https://www.ac24horas.com/2018/01/28/exclusivo-o-julgamento-sumario-e-execucoes-comandadaspelos-conselho-da-maior-faccao-do-acre-o-bonde-dos-13/> Acesso em abr. 2019.
} 


\section{SÃOPAULO $15 \sim 17 \cdot$ LISBOA $25 \sim 26$ JUN 2020}

BRASIL (2000). Constituição (1988). Emenda Constitucional ํo 26, de 14 de fevereiro de 2000.

BRASIL (2001). Estatuto da Cidade - Lei ํㅜ 10.257 de 10 de julho de 2001. Brasília, DF: Senado Federal, 2001.

BRASIL. Lei no 6.766, de 19 de dezembro de 1979.

BRASIL (2011). Diário do Senado Federal. 11 de fevereiro de 2011.

BRASIL (2017). Relatório Social Final da Cidade do Povo. Diagnóstico social da Cidade do Povo referente à pós-ocupação. Programa Habitacional Cidade do Povo. Estado do Acre. Rio Branco.

CNM - Confederação Nacional de Municípios (2015). Planos Diretores para Municípios de pequeno porte: limites e perspectivas para a aplicação dos instrumentos do Estatuto da Cidade. Brasília: CNM.

HOLANDA, A. C. G. (2011). Nova Política de Habitação De Interesse Social No Pará (2007-2010): Avanços e Limites. 177 f. Dissertação (Mestre em Planejamento do Desenvolvimento) - NAEA, UFPA, Belém, 2011.

IBGE - Instituto Brasileiro de Geografia e Estatística (2009). Estimativa da população de Rio Branco para o ano de 2009. Disponível em: http://www.ibge.gov.br/cidadesat/topwindow.htm?1> Acesso em: 10 julho de 2019 .

LIMA, R. B. e BONIFÁCIO, M. I. G. C. (2007). Habitantes e Habitat. João Pessoa: Editora Idéia.

LUIZ, L. A. C. (2009). Economia e responsabilidade socioambiental: gestão ambiental. São Paulo: Pearson Prentice hall.

MARICATO, E. (1995). Habitação e as políticas fundiária, urbana e ambiental. São Paulo: PNUD/MPO. (1995). A natureza do espaço. São Paulo: HUCITEC.

MORAIS, M. e VENTURATO, R. D. (2013). Reforma urbana nas cidades de Manaus (AM) e Rio Branco (AC): entre o "deslocamento" forçado e a "despossessão" de bens materiais e simbólicos. Contemporânea - Revista de Sociologia da UFSCar. São Carlos, v. 3, n. 1, jan-jun 2013, pp. 89-110.

MILLER JUNIOR, G. T. (2008). Ciência Ambiental. São Paulo: Cengage Learning.

NEPP/UNICAMP (1985). Núcleo de Estudos de Políticas Públicas da Universidade Estadual de Campinas. Políticas Demandas e Necessidades Habitacionais. Campinas: NEPP/UNICAMP/FECAMP/Fundação SEADE, março 1991.

OLIVEIRA, R. C. de. (2011). Estudo psicossocial e econômico das famílias atingidas por desastres naturais em áreas de risco na cidade de Rio Branco - Acre. Dissertação (mestrado) - Universidade Federal do Acre.

PIMENTEL, R. M. C. (2015). Moradias e segurança pública: o estudo de caso do Conjunto Habitacional Cidade do Povo - AC. Dissertação (mestrado) - Universidade de Brasília. 


\section{XII $\mathbf{S}$ ÃO PAULO $15 \sim 17 \cdot$ LISBOA $25 \sim 26$ JUN 2020}

RIO BRANCO (1986). Lei no 612.

RIO BRANCO (2006). Lei no 1.611.

RIO BRANCO (2012). Lei no 1.911.

SAITO, C. H. (1997). Política Nacional de Educação Ambiental e contrução da cidadania: desafios contemporâneos. In: RUSCHEINSKY, A. (Org.). Educação Ambiental: abordagens múltiplas. Porto Alegre: Artmed, 2002.SANTOS, M. (1997). Espaço e método. São Paulo: Nobel.

SCHMINK, M. e CORDEIRO, M. L. (2008). Rio Branco: a cidade da florestania. Belém: EDUFPA.

SOUZA NETO, C. P. de., SARMENTO NETO, D. (2012). Direito constitucional: teoria, história e métodos de trabalho. Belo Horizonte: Fórum.

UN HABITAT (2006). United Nations Human Settlements Program. New York: UN-HABITAT.

VILLAÇA, F. (1986). O que todo cidadão precisa saber sobre habitação. São Paulo: Global Editora. 